\title{
Meningkatkan Kreativitas dan inovasi bagi guru-guru SD pada pembelajaran muatan IPS melalui pengembangan media pembelajaran King Ludo berbasis kurikulum 2013 di Kota Tangerang Selatan
}

\author{
Ajat Sudrajat ${ }^{1}$, Ojat Darojat $^{2}$, Iwan $^{3}$, Syaeful Mikdar $^{4}$, Sri Sumiyati ${ }^{5}$, \\ Ary Purwantiningsih ${ }^{6}$, Sardjiyo $^{7}$, Irzan Tahar $^{8}$
}

\begin{abstract}
ajats@ecampus.ut.ac.id ${ }^{1}$; ojat@ecampus.ut.ac.id ${ }^{2}$; doniphj01@gmail.com³; mikdar@ecampus.ut.ac.id ${ }^{4}$; oneng@ecampus.ut.ac.id ${ }^{5} ;$ ary@ecampus.ut.ac.id ${ }^{6}$; sarjiyo@ecampus.ut.ac.id ${ }^{7}$; irsan@ecampus.ut.ac.id ${ }^{8}$

Universitas Terbuka $a^{1,2,4,5,6,7.8}$

SDN Pantai Harapan Jaya 01 Kecamatan Muaragembong Kabupaten Bekasi ${ }^{3}$
\end{abstract}

\begin{abstract}
The low learning outcomes of students in social studies subjects in SD need to find a solution so that the learning that is carried out can provide optimal results. One solution is to implement a learning medium that can create a comfortable learning environment for students. Learning media as a vehicle for providing learning experiences, as a means of communication to streamline the teaching and learning process, one of the learning media that is fun in learning is the learning media for playing King Ludo. The method used in carrying out this community service is a collaborative approach between proposers and partners. This approach needs to be done so that the implementation of activities goes according to plan and there are no technical obstacles. Reid (2004) mengemukakan bahwa collaborative learning memiliki lima tahapan, yaitu: 1) Engagement. 2) Exploration. 3) Transformation. 4) Presentation. 5) Reflection. Discussion King Ludo is a type of board game played by 2-4 players, where players compete to run their four pawns from start to finish based on the roll of the dice. The media of playing king ludo in this lesson is modified with the aim of improving social studies learning outcomes. King Ludo consists of ludo board, Ludo pawn, dice box, and magic box. Each media has different materials and functions, which will create an interesting and interactive game. The results of the Program Achievement Assessment of 30 participants stated that $100 \%$ had very significant benefits in order to increase the knowledge of teachers in South Tangerang City. While the partner's satisfaction with the implementation of PkM, this lecturer stated that $97.2 \%$ stated that they were very satisfied, this was indicated by the enthusiastic participants participating in this training until the specified time ended.
\end{abstract}

Keywords: IPS, King Ludo.

\begin{abstract}
ABSTRAK
Rendahnya hasil belajar siswa mata pelajaran IPS di SD perlu dicarikan suatu solusi agar pembelajaran yang dilaksanakan dapat memberikan hasil optimal. Salah satu solusinya adalah dengan menerapkan suatu media pembelajaran yang dapat menciptakan lingkungan belajar yang nyaman bagi siswa. Media pembelajaran sebagai wahana untuk memberikan pengalaman belajar, sebagai alat komunikasi guna mengefektifkan proses belajar mengajar, salah satu media pembelajaran yang menyenangkan dalam pembelajaran adalah media pembelajaran bermain King Ludo. Metode yang digunakan dalam melakukan pengabdian masyarakat ini yaitu dengan pendekatan kolaboratif antara pengusul dengan mitra. Pendekatan ini perlu dilakukan agar pelaksanakan kegiatan berjalan sesuai dengan rencana dan tidak ada halangan yang bersifat teknis. Reid (2004) mengemukakan bahwa collaborative learning memiliki lima tahapan, yaitu: 1) Engagement. 2) Exploration. 3) Transformation. 4) Presentation. 5) Reflection. Pembahasan King Ludo adalah model yang menggunakan papan catur dimainkan oleh 4 orang siswa, semua siswa bermain games memainkan bidak-bidak dari start sampai finish. King ludo ini adalah suatu games yang bertujuan untuk meningkatkan pembelajaran pada mata pelajaran IPS SD. Media King Ludo terdiri dari papan catur, bidak, dadu, gelas, dan kotak soal. Hasil Penilaian Ketercapaian Program dari jumlah peserta 30 orang menyatakan bahwa $100 \%$ memiliki kebermanfaatan yang sangat signifikan dalam rangka untuk menambah pengetahuan para guru yang berada di Kota Tangerang Selatan. Sedang kepuasan mitra terhadap pelaksanaan PkM dosen ini menyatakan 97.2\% menyatakan sangat puas hal ini ditandai dengan para peserta antusias mengikuti pelatihan ini sampai waktu yang ditentukan berakhir.
\end{abstract}

Kata kunci: IPS, King Ludo 


\section{PENDAHULUAN}

\section{Latar Belakang}

Berdasarkan observasi yang dilakukan di beberapa SD di Kota Tangerang Selatan Provinsi Banten khususnya pembelajaran IPS bahwa pembelajaran yang dilakukan oleh guru menggunakan pembelajaran secara konversional, akibatnya hasil belajar IPS sangat rendah dibawah nilai Kriteria Ketuntasan Minimal (KKM) yang telah ditentukan di sekolah. Berdasarkan uraian tersebut maka perlu dicarikan solusi yang baik, adapun solusi yang di buat adalah pengunaan media pembelajaran untuk lebih mengefektifkan proses belajar mengajar secara paripurna, maka salah satu media pembelajaran yang menyenangkan adalah media pembelajaran dengan King Ludo. King ludo dapat digunakan di sekolah dasar untuk mempermudah dalam pembelajaran IPS karena media king ludo merupakan media yang menarik bagi siswa untuk belajar IPS serta dapat menciptakan pembelajaran yang aktif, kreatif dan menyenangkan.

Berdasarkan masalah di atas, rumusan masalah dalam PkM Dosen-UT yaitu: "Bagaimanakah meningkatkan Kreativitas dan inovasi bagi guru-guru SD pada pembelajaran muatan IPS melalui pengembangan media pembelajaran King Ludo berbasis kurikulum 2013 di Kota Tangerang Selatan-Banten ?”

Kegiatan PkM dosen-UT ini dilakukan dengan kegiatan workshop pembuatan dan pengembangan King Ludo bagi guru SD di Kota Tangerang Selatan-Banten. Guru praktek pembuatan King Ludo dan Perangkat pembelajaran Berbasis Kurikulum 2013 (Bahan Ajar, Media pembelajaran, LKPD, dan Evaluasi). sehingga diharapkan para guru dapat mengunakaan media pembelajaran yang bervariasi dan inovatif dan pada akhirnya dapat meningkatkan hasil belajar mata pelajaran IPS siswa SD.

\section{Manfaat PkM Dosen-UT}

Secara khusus manfaat PkM Dosen-UT adalah : 1) siswa, pembelajaran IPS lebih menyenangkan dan bervariasi serta tidak membosankan; 2) guru, menemukan inovasi pembelajaran dalam kegiatan belajar mengajar; 3)sekolah, meningkatkan mutu sekolah melalui aktivitas guru yang produktif sehingga mencapai sasaran.

\section{KAJIAN LITERATUR DAN TEORI}

Hasil belajar IPS ditentukan oleh berbagai faktor yang mempengaruhinya. Faktor yang mempengaruhi hasil belajar Ilmu Pengetahuan Sosial dapat berupa faktor internal, seperti minat dan kesiapan belajar, serta faktor eksternal seperti bahan ajar dan gaya belajar (learning style). Selain faktor-faktor di atas, kemampuan kecerdasan siswa dan kondisi fisiknya yang berhubungan dengan panca indera, juga dapat berpengaruh terhadap hasil belajar Ilmu Pengetahuan Sosial siswa.

Faktor Media pembelajaran sangat berhubungan dengan keadaan siswa secara objektif, dalam hal ini pengalaman dan tingkat intelegensi. Tersedianya bahan ajar yang memberi kemudahan bagi siswa untuk mempelajarinya, sehingga mendapatkan hasil belajar yang lebih baik. Minat belajar siswa sangat berpengaruh terhadap hasil belajar Ilmu Pengetahuan Sosial, karena minat merupakan dorongan instrinsik yang sangat besar untuk melakukan suatu kegiatan. Dengan minat dan rasa ingin tahu yang besar terhadap Ilmu Pengetahuan Sosial, maka keinginan untuk belajar dan berusaha memahami Ilmu Pengetahuan Sosial dapat terlihat dengan jelas. Kesiapan belajar adalah wujud penyerapan pengetahuan dan pengalaman belajar yang berlangsung pada fungsi kognitif. Faktor ini sangat berhubungan dengan tahapan perkembangan secara kognitif. Dalam pelajaran Ilmu Pengetahuan Sosial, jika materi dianggap terlalu rumit dan abstrak, serta strategi, pendekatan, dan metode yang dipilih untuk kegiatan belajar siswa tidak cukup menunjang kejelasan pada diri siswa, maka hasil belajar yang diharapkan tidak akan tercapai dengan baik. Oleh karena itu materi yang dianggap rumit dan abstrak harus disajikan dengan media belajar yang tepat sehingga dapat mengurangi atau bahkan menghilangkan sifat abstrak pada materi ajar tersebut. Demikian pula dengan strategi, pendekatan, dan metode harus disesuaikan dengan tingkat pemahaman siswa serta keragaman dan tingkat kesukaran bahan ajar. Dengan demikian hasil belajar yang diharapkan akan tercapai.

Dengan demikian hasil belajar Ilmu Pengetahuan Sosial dalam penelitian ini adalah perubahan tingkah laku dan kemampuan berpikir siswa. 


\section{METODE}

Metode pada PkM Dosen Universitas Terbuka ini yaitu dengan pendekatan kolaboratif. Menurut Reid (2004) collaborative learning yaitu: 1) Engagement; Dosen melakukan penilaian terhadap kemampuan, minat, bakat dan kecerdasan awal para guru. 2) Exploration; Dosen memberi tugas berupa permasalahan yang terjadi dilingkungannya. 3) Transformation; setiap guru saling bertukar pikiran dan melakukan diskusi kelompok. 4) Presentation; kelompok mempresentasikan hasil diskusinya. 5) Reflection; terjadi proses Tanya-jawab antar kelompok.

Sedangkan aktivitas pada PkM Dosen-UT tahun 2020 meliputi:

1) Pelatihan; Narasumber memberikan pengetahuan yang di milikinya, dengan tema:

a. Konsep belajar dan pembelajaran oleh Syaeful Mikdar, Sardjiyo.

b. Hakikat Media pembelajaran oleh Irzan Tahar, Sri Sumiyati.

c. Praktek pembuatan Media Pembelajaran oleh Ajat Sudrajat, Iwan, dan Ary Purwantiningsih.

d. Pembelajaran jarak jauh oleh Ojat Darojat.

2) Tanya jawab: peserta pelatihan menanyakan konsep atau bahan yang belum dapat dipahami.

3) Diskusi; peserta dibagi dalam beberapa kelompok untuk pembuatan media pembelajaran King Ludo.

Metode dan langkah-langkah tersebut dilakukan untuk terselenggaranya acara dengan baik dan sedapat mungkin dapat mencapai tujuan yang diinginkan.

Kegiatan pengabdian pada masyarakat ini tentu tidak akan berhasil tanpa partisipasi dan dukungan dari berbagai pihak. pihak-pihak yang yang terlibat dalam PkM Dosen Universitas Terbuka adalah :

a. Dinas Pendidikan dan Kebudayaan Kota Tangerang Selatan; pihak yang memberikan ijin pelaksanan PkM Dosen Universitas Terbuka.

b. Kelompok kerja Kepala Sekolah Kecamatan.

c. Kelompok Kerja Guru masing-masing Kecamatan

Evaluasi pelaksanaan program perlu dilakukan untuk memantau sejauh mana program-program kegiatan pengabdian pada masyarakat Dosen FKIP Universitas Terbuka ini bisa efektif sesuai dengan rencana. Evaluasi akan dilakukan terhadap kegiatan-kegiatan sebagai berikut: Sasaran evaluasi bisa dilihat dari jumlah peserta yang hadir, aktivitas peserta pada saat platihan berlangsung, serta dorongan atau animo dari para guru terhadap kegiatan yang dilaksanakan. Program pengabdian kepada masyarakat ini sangat baik dalam rangka mengurangi perilakuperilaku menyimpang pada anak-anak remaja. Oleh karena itu program ini perlu berlanjut. Keberlanjutan program ini bisa dilakukan dengan dijadikan sebagai wilayah binaan PkM Universitas Terbuka.

\section{HASIL DAN PEMBAHASAN}

\section{Deskripsi King Ludo dalam Pembelajaran IPS SD}

King Ludo merupakan sejenis papan permainan yang dimainkan 4 orang siswa, siswa berusaha memainkan king ludo dari awal sampai akhir. Adapun alat dan bahan King Ludo adalah papan, pion, kotak dadu, dan kotak soal.

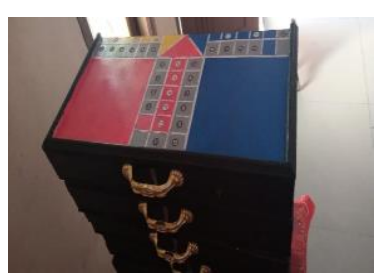

Gambar 1: Papan catur

Papan catur dalam permainan ini berbentuk segi empat, didalamnya terdapat home base dengan empat warna berbeda yaitu merah, hijau, kuning, dan biru.

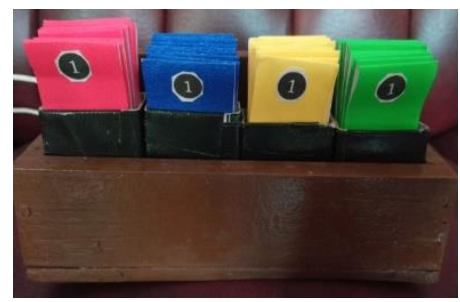


Soal terdiri dari soal-soal yang telah disusun berdasarkan tema atau subtema dalam pembelajaran, jumlah soal disesuaikan dengan alokasi waktu yang tersedia.

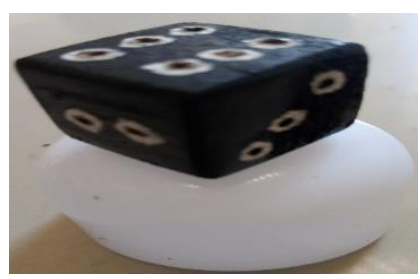

Gambar 3: Dadu dan mangkok

Dadu terbuat dari bahan yang aman dan terdiri dari angka 1,2,3,4,5 dan 6. Sedangkan mangkok terbuat dari bahan plastik yang tidak mudah pecah tapi diupayakan warnanya cerah sehingga menarik siswa.

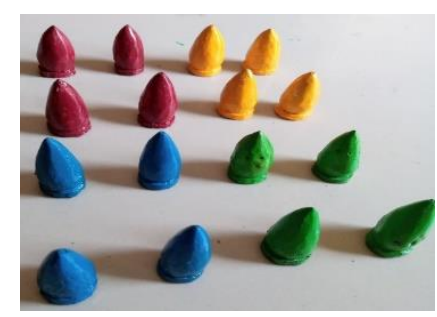

Gambar 4: Bidak

Bidak terbuat dari bahan yang ringan dan menarik. Kemudian diberi warna yang menarik sesuai dengan papan king ludo tersebut.

Langkah-langkah King ludo menurut Iwan (2018) adalah sebagai berikut:

a) Siswa melakukan hum-pin-pa untuk memulainya games ini.

b) Siswa yang mendapatkan kesempatan pertama boleh memilih warna yang akan dimainkan disimpan pada papan warna yang dipilih.

c) Siswa memulai memainkan bidak secara bergantian.

d) Supaya bisa bidak ke luar dari kota, siswa diusahakan memperoleh angka enam dari dadu yang dilemparkan.

e) Siswa memainkan bidak yang berada pada jalur lintasan permainan sesuai hasil lemparan dadu.

f) Siswa mengambil soal sesuai lemparan dadu yang muncul. Kemudian siswa menjawab soal tersebut jika benar siswa akan mendapatkan poin dan bisa lanjut lagi ke permainan berikutnya.

g) Bila siswa mengundi mendapatkan angka enam, siswa boleh menggerakkan bidak yang berada di jalur atau mengeluarkan bidak yang berada di home base.

h) Bila bidak pemain berhenti di tempat yang telah terisi bidak lawan maka bidak tersebut mati dan masuk kembali ke home base milik lawan.

i) Bidak yang sudah melewati satu putaran masuk ke dalam jalur berwarna sesuai dengan warna bidak tersebut.

j) Bidak tidak akan bergerak apabila angka yang dihasilkan dadu belum sesuai untuk masuk ke dalam finish.

Ellis (2011) menjelaskan bahwa Kelebihan King Ludo, yaitu : a) proses belajar mengajar menjadi lebih menarik siswa sehinggah meningkatkan hasil belajar IPS; b) pembelajaran lebih dipahami oleh para siswa; c) model pembelajaran inovatif; d) siswa lebih aktif dan kreratif. 
Sedangkan Ellis (2011) menyatakan kelemahan King Ludo yaitu : a) guru dituntut lebih kreatif; b) melebihi jam yang sudah ditentukan; c) menyita anggaran guru; (d) guru harus membuat soal-soal yang bervariasi.

\section{Pembahasan PkM Dosen Universitas Terbuka}

Kegiatan ini diikuti oleh 30 guru sebagai peserta yang terdiri dari guru SD yang ada di Kota Tangerang Selatan-Banten dimana proses pemilihan guru tersebut yang masih muda dan fres dengan harapan guru muda tersebut memiliki semangat untuk mengembangkan dan mengimplementasikan media pembelajaran king ludo di sekolahnya masing-masing. Kegiatan ini dilaksanakan pada tanggal 4 Oktober 2020 bertempat di SDN Ciputat 04 Kota Tangerang Selatan Provinsi Banten.

Kegiatan workshop media pembelajaran king ludo ini dilakukan dengan cara, yaitu: Pertama, pemberian teori king ludo. Pada materi ini peserta diberikan teori-teori pembelajaran dan praktek penggunaan langsung media pembelajaran King Ludo. Kedua, implementasi dan penerapan media pembelajaran King Ludo di Sekolah SDN Bakti Jaya Pamulang. Kemudian narasumber mengadakan monitoring pelaksanaan pembelajarannya dalam rangka penyerapan konsep King ludo dari guru ke siswa sebagai upaya bahwa pembelajaran mata pelajaran IPS menyenangkan dan bermakna serta pada akhirnya meningkatkan hasil belajar IPS pada jenjang SD.

Hasil Penilaian Ketercapaian Program dari jumlah peserta 30 orang menyatakan bahwa 100\% memiliki kebermanfaatan yang sangat signifikan dalam rangka untuk menambah pengetahuan para guru yang berada di Kota Tangerang Selatan. Sedang kepuasan mitra terhadap pelaksanaan PkM dosen ini menyatakan 97.2\% menyatakan sangat puas hal ini ditandai dengan para peserta antusias mengikuti pelatihan ini sampai waktu yang ditentukan berakhir.

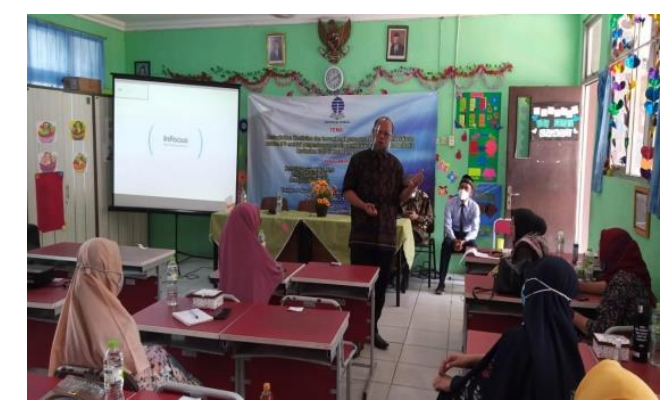

Gambar 1: Narasumber Prof. Ojat Darojat, M.Bus., Ph.D, sedang memberikan materi Pembelajaran Jarak Jauh dan Merdeka Belajar

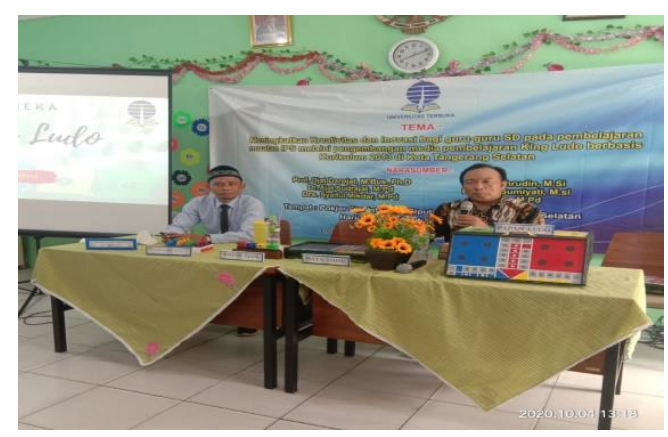

Gambar 2 : Narsumber Dr. Ajat Sudrajat, M.Pd dan Iwan, S.Pd.,M.Pd sedang menjelaskan praktek pembuatan media pembelajaran king ludo pada guru-guru peserta. 


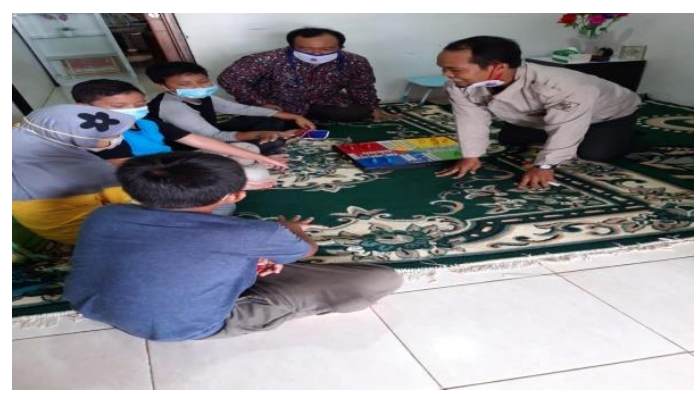

Gambar 3: Monitoring pelaksanaan pembelajaran IPS dengan menggunakan King Ludo di kelompok belajar SDN Bakti Jaya

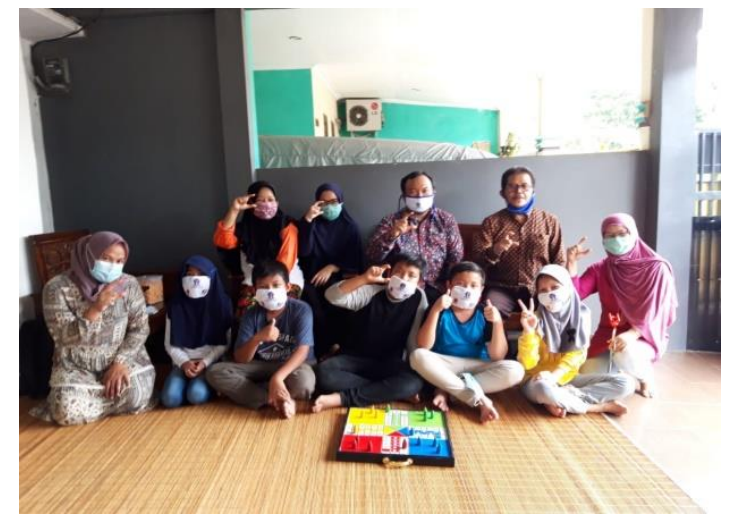

Gambar 4: Monitoring pelaksanaan pembelajaran IPS dengan menggunakan King Ludo di kelompok belajar bersama dengan Kepala Sekolah SDN Bakti Jaya.

\section{KESIMPULAN DAN SARAN}

\section{Kesimpulan}

Dari hasil workshop King Ludo ini didapatkan bahwa :

a. Guru diharapkan sudah dapat memahami media pembelajaran king ludo secara baik.

b. Guru dapat mengimplementasikan dan menerapkan media pembelajan king ludo pada pembelajaran IPS sehingga dapat meningkatkan hasil belajar IPS SD.

c. Hasil Penilaian Ketercapaian Program dari jumlah peserta 30 orang menyatakan bahwa $100 \%$ memiliki kebermanfaatan yang sangat signifikan dalam rangka untuk menambah pengetahuan para guru yang berada di Kota Tangerang Selatan. Sedang kepuasan mitra terhadap pelaksanaan PkM dosen ini menyatakan 97.2\% menyatakan sangat puas hal ini ditandai dengan para peserta antusias mengikuti pelatihan ini sampai waktu yang ditentukan berakhir.

\section{Saran}

Saran yang diajukan adalah :

a. Perlu adanya workshop sejenis dalam rangka meningkatkan mutu pembelajaran di kelas pada jenjang Sekolah Dasar.

b. Perlu adanya perubahan daya berfikir guru dalam rangka merubah strategi pembelajaran di kelas sehingga pada akhirnya meningkatkan hasil belajar IPS.

\section{DAFTAR PUSTAKA}

[1] Ellis Meiliasari., Upaya Peningkatan Hasil Belajar IPS Melalui Media Permainan Ludo Materi Proklamasi Kemerdekaan RI Pada Siswa Kelas V Semester 2 SD Negeri Gumpang 01 Kartasura Tahun Pelajaran 2010/2011 (Skripsi, Fakultas Keguruan Dan Ilmu Pendidikan Universitas Muhammadiyah Surakarta, 2011)

[2] Iwan, Peningkatan Hasil belajar IPS Melalui pembelajaran Bermain king Ludo Clasroom action research V SDN Pantai Harapan Jaya 01 Kecamatan Muaragembong Kabupaten Bekasi. Tesis: UNJ 2018.

[3] Nasution, Metode Penelitian Naturalistik Kualitatif, (Bandung: Tarsito, 1996)

[4] Reid Enhancing Student thinking through Collaboration Learning, 2004. (http//www.ed.gov/database/ERIC_Digest/ ) 
p-ISSN : 2655-7304

e-ISSN : 6655-8953

[5] Sasmita Sindy Intan Mawarni Amkas, I Made Tegeh, Luh Putu Putrini Mahadewi., Pengembangan Media Ludo Word Game Siswa Kelas IV SDN 1 Banjar Bali Tahun Pelajaran 2017/2018 (e-Journal Edutech Jurusan Teknologi Pendidikan Vol. 8 No. 2: Universitas Pendidikan Ganesha, 2017) 